\title{
As bases experimentais da lesão por isquemia e reperfusão do fígado. Revisão ${ }^{1}$
}

Luiz Eduardo C. Miranda ${ }^{2}$, Fernanda Viaro ${ }^{3}$, Reginaldo Ceneviva ${ }^{4}$, Paulo Roberto B. Evora $^{5}$

\begin{abstract}
Miranda LEC, Viaro F, Ceneviva R, Évora PRB. As bases experimentais da lesão por isquemia e reperfusão do fígado: revisão. Acta Cir Bras [serial online] 2004 Jan-Fev;19(1). Disponível em URL: http://www.scielo.br/acb.

RESUMO - O transplante hepático tornou-se o procedimento de escolha para o tratamento da doença hepática terminal. Não obstante o sucesso da cirurgia, a disfunção pós-operatória do fígado enxertado ainda representa importante causa de morbidade e mortalidade. O restabelecimento do fluxo sangüíneo ao fígado recém transplantado impõe a ele nova agressão, agravando a lesão causada pelo período de isquemia. Este fenômeno pouco compreendido é conhecido como lesão por isquemia e reperfusão e envolve disfunção endotelial, seqüestro de leucócitos e agregação de plaquetas, lesão por radicais livre de oxigênio, e distúrbios da microcirculação hepática. Essa revisão discute os vários aspectos fisiopatológicos que estão envolvidos na lesão por isquemia e reperfusão do fígado.
\end{abstract}

DESCRITORES - Isquemia e reperfusão. Fígado.

\section{Introdução}

O transplante hepático tornou-se o tratamento de escolha para pacientes com insuficiência hepática terminal e hepatite aguda fulminante. A sobrevida dos pacientes submetidos a transplante hepático tem melhorado dramaticamente. Em 1980 somente $50 \%$ dos pacientes transplantados sobreviviam a um ano de cirurgia. Em 1996, a maioria dos serviços que realizavam o transplante hepático anunciava taxa de sobrevida maior que $85 \%$ em um ano, e de aproximadamente $75 \%$ em cinco anos de evolução pósoperatória. Não obstante o sucesso dessa cirurgia, a disfunção primária do enxerto representa importante causa de morbidade e mortalidade para pacientes operados ${ }^{1-5}$. Ao restaurar o fluxo sangüíneo, impõe-se nova agressão ao fígado enxertado, agravando-se a lesão causada pelo período de isquemia. Esse fenômeno é conhecido como lesão de isquemia e reperfusão e envolve mecanismos e vias metabólicas celulares complexas, em que o resultado final comum é a disfunção do enxerto. No fígado a lesão de isquemia e reperfusão pode ser causada por choque hemorrágico, sepse tardia cirurgia para grandes traumas, ressecção de grandes tumores e transplante hepático. Qualquer fígado transplantado apresenta alguma extensão de disfunção, já que a lesão de isquemia-reperfusão é fenômeno inevitável para todo órgão transplantado. A reperfusão após período de isquemia resulta em dois efeitos principais: a perda da viabilidade do endotélio dos sinusóides e a ativação das células de Kupffer e neutrófilos. O primeiro efeito provoca importante distúrbio da microcirculação, aderência de leucócitos e plaquetas, com conseqüente diminuição do fluxo sangüíneo e perpetuação do processo de isquemia. Vasoconstricção, resultante do desequilíbrio entre o efeito de óxido nítrico e endotelinas, agrava o distúrbio da microcirculação. A ativação das células de Kupffer e leucócitos provocam liberação de radicais livres de oxigênio óxido nítrico, além de outros mediadores pró-inflamatórios que provavelmente agravam a lesão do enxerto. A lesão do endotélio pode impedir a liberação do óxido nítrico, molécula bioativa que só recentemente teve a sua importância reconhecida e que parecer ter papel central na lesão de isquemia e reperfusão do fígado.

Esse artigo de revisão aborda os principais eventos associados à lesão de isquemia e reperfusão do fígado, levando em consideração os principais aspectos envolvidos nesse processo. Foram selecionadas apenas algumas referências que estão assinaladas nos itens e subitens do texto, que se constituiu na monografia para a pré-qualificação do autor

1. Trabalho realizado no Laboratório de Função Endotelial do Departamento de Cirurgia e Anatomia da Faculdade de Medicina de Ribeirão Preto USP

2. Doutor em Clínica Cirúrgica pela Faculdade de Medicina de Ribeirão Preto - USP.

3. Biomédica e Pesquisadora do Laboratório de Função Endotelial do Departamento de Cirurgia e Anatomia da Faculdade de Medicina de Ribeirão Preto - USP.

4. Professor Titular do Departamento de Cirurgia e Anatomia da Faculdade de Medicina de Ribeirão Preto - USP.

5. Professor Livre-Docente e Chefe do Laboratório de Função Endotelial do Departamento de Cirurgia e Anatomia da Faculdade de Medicina de Ribeirão Preto - USP. 
para defesa de Tese de Doutoramento junto ao Departamento da Cirurgia e Anatomia da Faculdade de Medicina de Ribeirão Preto da Universidade de São Paulo. Foi selecionado um número superior a duzentas referências, que torna a publicação muito extensa. Ao leitor, que porventura venha a se interessar pelo levantamento bibliográfico completo, este poderá ser fornecido pelos autores.

\section{A lesão provocada por isquemia e reperfusão do fígado ${ }^{6}$}

Em situações de ausência de oxigênio inicia-se seqüência de eventos químicos que provocarão disfunção celular, edema celular e intersticial e finalmente morte celular. A célula, privada de seu combustível básico, passa a obter energia por meio do metabolismo anaeróbico, o que resulta em acidose lática. $\mathrm{O}$ meio ácido é inadequado para a cinética normal das enzimas, privando a célula dos seus mecanismos para manutenção da homeostase. As alterações celulares secundárias a hipóxia são bem documentadas. O sofrimento da membrana plasmática provoca alterações eletrolíticas que acompanhadas pelas perdas dos mecanismos de produção de ATP levam à perda da capacidade de síntese celular. O cálcio provoca disfunção da membrana mitocondrial e lesão irreversível. Segue-se autólise secundária à isquemia (edema dos lisossomos, vacuolização do retículo endoplasmático, vazamento de enzimas e proteínas e descaracterização da compartimentalização celular). A integridade das membranas não pode ser mantida e a célula morre.

A reperfusão tem duas conseqüências benéficas: A oferta de energia é restaurada e os metabólitos tóxicos são removidos. Entretanto, a reperfusão causa graves conseqüiências metabólicas e maior lesão tecidual que a causada pela isquemia. A reperfusão acarreta efeitos metabólicos sistêmicos em razão do retorno de sangue com $\mathrm{pH}$ ácido e rico em potássio para a circulação sistêmica. $\mathrm{O}$ mecanismo por meio do qual a reperfusão causa lesão celular é mal compreendido, e oferece inúmeras e excitantes possibilidades de pesquisa, haja vista a grande variedade de fenômenos envolvidos na lesão.

\section{O fenômeno do não-refluxo}

Obstrução da microcirculação torna a tentativa de reperfusão ineficaz. Esse fenômeno, conhecido em língua inglesa como "no-reflow phenomenon" é dependente do tempo de isquemia e é pouco entendido. Quatro teorias têm sido apresentadas para explicá-lo: a) o fluxo sangüíneo estaria impedido pelo edema celular, intersticial, ou ambos; b) ocorreria autoregulação inapropriada do fluxo sangüíneo, causado pelo decréscimo na demanda metabólica do tecido pós-isquêmico; c) o sofrimento do músculo liso resultaria em perda da capacidade de relaxamento em resposta aos mecanismos normais; d) a lesão do endotélio levaria a desvios na produção de fatores implicados na regulação do fluxo de sangue.

\section{Os neutrófilos}

As lesões locais e sistêmicas da isquemia e reperfusão estão associadas com o acúmulo de neutrófilos da microvasculatura. A interação entre neutrófilos e endotélio é pré-requisito obrigatório para a lesão microvascular induzida por isquemia e reperfusão, fator ativador de plaquetas (PAF), leucotrieno (LT) B4 e radicais livres de oxigênio são os prováveis mediadores da resposta. Neutrófilos ativados, isto é, aqueles que expressam proteínas de adesão, fixam-se e migram através do endotélio, causando destruição de tecidos pela liberação de radicais livres, enzimas proteolíticas e peroxidase. O uso de anticorpos monoclonais contra leucócitos, o que causa importante leucopenia, é capaz de proteger o fígado da lesão de isquemia e reperfusão, permitindo a completa recuperação dos valores de ATP hepático. Experimentos claramente demonstram que a isquemia e reperfusão induzem ao acúmulo de neutrófilos no fígado, e que radicais livres superóxidos são importantes mediadores no mecanismo de recrutamento dessas células inflamatórias ${ }^{7}$

\section{As células de Kupffer ${ }^{8,9}$}

As células de Kupffer podem gerar vários mediadores inflamatórios, incluindo radicais livres e citocinas, e, portanto desempenham papel central na lesão de isquemia e reperfusão do fígado. Há indícios de que as células sejam ativadas logo nos primeiros momentos da reperfusão. A oferta de gadolinium, um supressor da atividade das células de Kupffer, atenua a lesão de isquemia e reperfusão hepática, ao passo que a oferta de partículas de látex, que ativam as células de Kupffer, agrava a lesão de isquemia e reperfusão. Células de Kupffer isoladas de tecido que sofreram lesão de isquemia e reperfusão liberam quantidades aumentadas de radicais livres. Estudos que se preocuparam com a modulação da função das células de Kupffer mostram que essas células desempenham importante papel na lesão de reperfusão e que o ânion superóxido liberado por elas pode ser o principal implicado nesse processo. Há evidências de que as células de Kupffer sejam as principais produtoras de citocinas em situações de ir hepática. Mesmo células de Kupffer que estão em áreas não isquêmicas do fígado parecem ser ativadas em situação de isquemia e reperfusâo. A manipulação da atividade dessas células pode representar interessante caminho para atenuar a lesão de isquemia e reperfusão do fígado transplantado.

\section{A adenosina $a^{10}$}

A adenosina é componente endógeno produzido pela ação de várias enzimas no trifosfato, bifosfato e monofosfato de adenosina. Exerce seu papel protetor na lesão de isquemia e reperfusão por promover vasodilatação, inibição da agregação de plaquetas e aderência de neutrófilos, inibição da síntese de endotelinas e radicais livres e aumento da produção do óxido nítrico. Durante a isquemia a adenosina entra no compartimento intracelular onde é convertida a inosina. Durante a reperfusão a inosina é lavada dos tecidos, privando-os dos efeitos benéficos da adenosina, ou é convertida a hipoxantina e xantina, fomentado a síntese de radicais livres. O aumento da adenosina endógena melhora a sobrevida, a função hepática, $o$ fluxo sanguíneo hepático e os parâmetros histológicos em modelos animais de lesão de isquemia e reperfusão.

\section{$O$ pré-condicionamento ${ }^{11}$}

O fenômeno do pré-condicionamento refere-se ao fato dos tecidos adquirirem resistência aos efeitos deletérios da lesão de isquemia e reperfusão por meio da exposição prévia a breves períodos de oclusão vascular. O efeito do pré-condicionamento foi primeiro demonstrado no coração, e depois no fígado. Esse efeito 
pode ser resultado, em parte, da liberação de adenosina pelo tecido isquêmico. Postula-se que os efeitos benéficos da adenosina sejam mediados por óxido nítrico, já que podem ser abolidos por inibidores da síntese de óxido nítrico, além da detecção da expressão da forma induzível da óxido nítrico sintase pela manobra de Pringle. Muitos outros aspectos do précondicionamento são estudados. O précondicionamento protege as células endoteliais dos sinusóides contra a morte, e suprime a ativação das células de Kupffer após conservação a frio e reperfusão do fígado. Aparentemente o metabolismo de células de Kupffer e a síntese de prostaglandinas não são mediadores do précondicionamento isquêmico das células endoteliais. O pré-condicionamento protege tecido à distância do órgão reperfundido. Embora o pré-condicionamento não modifique a infiltração de leucócitos no fígado durante a reperfusão, em órgãos remotos ele previne a infiltração de leucócitos, e reduz o estresse oxidativo e os distúrbios da microcirculação em situações de lesão de isquemia e reperfusão hepática. Esse efeito parece ser mediado inibição da liberação de fator de necrose tumoral por células de Kupffer, e envolve a regulação da expressão de P-selectinas.

\section{O fator nuclear $k B^{12}$}

Um fator comum entre os mediadores da lesão de isquemia e reperfusão é a sua transcrição nuclear. A transcrição da forma induzível da NOS, citocinas, moléculas de aderência, TNF-a e outros mediadores é em parte controlada pelo fator nuclear $\mathrm{kB}$.

As propriedades do fator nuclear $\mathrm{kB}$ são fortemente reguladas por proteínas inibitórias (I)- kB. Em situações de estresse oxidativo, I-kB é degradado, permitindo a translocação de fator nuclear $\mathrm{kB}$ para $\mathrm{o}$ núcleo. Em modelos animais a ação do fator nuclear $\mathrm{kB}$ foi inibida por $\mathrm{N}$-acetilcisteína, sugerindo que a sua ativação durante a lesão de isquemia e reperfusão hepática é mediada por radicais livres.

\section{O endotélio ${ }^{13,14,15}$}

O endotélio modula o tônus da musculatura lisa por meio da liberação de vários hormônios locais e autacóides que incluem metabólitos do ácido aracdônico, (prostaciclina PGI2, tromboxane A2 e
LTB4, óxido nítrico e endotelinas). Também tomam papel na modulação da resposta o PAF, complemento e citocinas. O endotélio modifica a resposta inflamatória por regular a expressão de moléculas de aderência que se ligam as integrinas dos leucócitos, para mediação da infiltração dessas células, além de ter papel significante no transporte de lipídios, coagulação e reatividade imunológica. Estudos com perfusão hepática "in situ" suportam o importante papel funcional do óxido nítrico para a regulação da circulação intrahepática no sistema portal em ratos normais.

Em situações de isquemia e reperfusão, parece haver desequilíbrio do delicado balanço entre endotelinas e óxido nítrico. Nos primeiros momentos da reperfusão as concentrações de endotelinas estão aumentadas tanto no plasma como no fígado, e esse fato está correlacionado com a diminuição do fluxo sangüíneo. Por outro lado, as concentrações de óxido nítrico estão diminuídas durante as primeiras horas da reperfusão. Há evidências de que a interferência no desequilíbrio entre endotelinas e óxido nítrico pode causar benefícios ao órgão enxertado. O endotélio é tecido extremamente sensível a lesão por isquemia e reperfusão, situação em que perde a sua capacidade de gerar óxido nítrico. Esse fato pode contribuir para a lesão por isquemia e reperfusão, em razão dos efeitos conhecidos do óxido nítrico. Embora a lesão do endotélio de artérias coronárias pareça estar intimamente relacionada à lesão do miocárdio em situações de isquemia e reperfusão, as fases iniciais da lesão por isquemia e reperfusão hepáticas parecem não depender da lesão do endotélio da artéria hepática.

\section{O óxido nítrico ${ }^{16,17,18,19,20,21}$}

O papel metabólico do óxido nítrico no fígado ainda é pouco conhecido. Muito do que se encontra na literatura diz respeito às várias isoformas de NOS que foram identificadas. Há enorme interesse no papel das células de Kupffer, já que elas são capazes de produzir óxido nítrico e estão claramente implicadas na lesão de isquemia-reperfusão. O óxido nítrico pode desempenhar papel citotóxico ou citoprotetor para o fígado. Entre os efeitos citoprotetores está o seu papel como sequies- trador de radicais livres, aumento da síntese de DNA para o reparo de enzimas, diminuição da síntese durante a isquemiareperfusão, bloqueio da liberação de $\mathrm{PGE}_{2}$ e $\mathrm{PGF}_{2}$ ae a diminuição do crescimento de células tumorais. Os seus efeitos citotóxicos estariam na sua propriedade de reagir com superóxidos para formar superóxidos nitrogenados extremamente reativos e que provocam inativação de canais de cálcio, inibição da respiração mitocondrial e nitrosação de moléculas de transdução e tirosina. O óxido nítrico também pode inibir a ativação do citocromo $\mathrm{P}_{450}$, diminuir a produção de proteínas de fase aguda, aumentar a peroxidação de lipídios, etc.

Há evidências de que o óxido nítrico tenha papel protetor da microcirculação hepática em casos de isquemia e reperfusão, atenuando os efeitos da lesão no tecido hepático. A inibição da síntese de óxido nítrico durante a reperfusão, obtida por meio da infusão contínua de L-NAME, provoca evidente diminuição no fluxo sangüíneo sinusoidal. Embora a inibição da NOS diminua a formação de peróxinitrito durante a fase de reperfusão, ela aumenta a lesão hepática e o acúmulo de neutrófilos no fígado, sugerindo que a função antiinflamatória do óxido nítrico é mais importante do que o potencial citotóxico representado pelo acúmulo de peróxinitrito. Há dados que sugerem que as endotelinas, mediadores endoteliais com potentes efeitos vasoativos, tenham efeitos antagônicos aos do óxido nítrico: bloqueio da síntese de óxido nítrico usando-se L-NAME durante a fase de reperfusão implica na prevenção do aumento sérico de nitratos e nitritos, e clara piora na circulação sinusoidal. Ao contrário, o uso de bosentam, droga antagonista dos receptores de endotelinas $\mathrm{A}+\mathrm{B}$, restaura a densidade funcional dos sinusóides e a $\mathrm{PO}_{2}$ de superfície a valores basais. Há vários trabalhos, empregando metodologias diferentes entre si e avaliando parâmetros variados, demonstrando que a oferta de L-arginina exógena protege o fígado contra a lesão de isquemia-reperfusão. A formação endógena de óxido nítrico pode ter papel benéfico na proteção do fígado, inclusive em casos de isquemia e reperfusão de órgãos e tecidos à distância do fígado. A administração de inibidor não seletivo da óxido nítrico sintase, Nw-nitroL-arginina (L-NNA) 30 minutos antes de 
se provocar isquemia e reperfusão no fígado causa importante agravamento da lesão hepática, efeito que pode ser parcialmente prevenido pela oferta simultânea de L-arginina, precursor endógeno de óxido nítrico. O óxido nítrico tem também efeito protetor por limitar a infiltração de leucócitos induzida por isquemia e reperfusão, já que o tratamento de animais com Nwnitro-L-arginina metil-éster-hidroclorido (L-NAME) agrava a estase de leucócitos no fígado, ocorrendo o contrário com a administração conjunta de L-arginina. A inibição da síntese de óxido nítrico com LNAME agrava a lesão de reperfusão e endotoxemia causada por endotoxina de Salmonella enteritidis, enquanto que o tratamento com L-arginina é capaz de restaurar os parâmetros avaliados aos valores dos animais controles. Por outro lado, ratos tratados com L-NAME imediatamente antes da reperfusão tiveram lesão tecidual semelhante ao grupo controle e significativamente menor do que ratos com isquemia e reperfusão e ratos que receberam L-arginina. Para esses mesmos grupos não houve diferenças com relação a lipoperoxidação, sugerindo mecanismo de lesão independente dela. Nesse experimento L-NAME não mudou a peroxidação dos lipídios, mas claramente reduziu a lesão de reperfusão. Parece não haver aumento na geração local ou sistêmica de óxido nítrico ou peróxinitrito durante a reperfusão, e, portanto é pouco prováveis que qualquer um desses metabólitos estejam envolvidos no estresse oxidativo e lesão hepática durante o tempo de reperfusão do fígado. Além disso, peróxinitrito, se injetado localmente na veia Porta, claramente atenua a interação entro leucócitos e endotélio e inibe a infiltração de leucócitos, reduzindo a lesão de reperfusão dependente de leucócitos.

\section{Atividade da NOS durante o} período de isquemia e reperfusão hepática ${ }^{22,23,24,25,26}$

O óxido nítrico é sintetizado a partir da Larginina pela ação de uma única enzima, a óxido nítrico sintase (NOS). Existem várias isoformas de óxido nítrico sintase que foram subdivididas em categorias, três delas reconhecidas como básicas: NOS-1 (ncNOS), a forma neural e constitutiva; NOS-2 (iNOS), a forma induzível que é produzida no organismo mediante apropriada indução; NOS-3 (eNOS), que é a forma constitutiva e localizada no endotélio. eNOs e ncNOS são dímeros complexos dependente da calmodulina, enquanto iNOS é formada por complexo tri e tetramérico e não depende da ligação à calmodulina. Somente a eNOS e iNOS estão presentes no fígado e têm papel importante na lesão por isquemia e reperfusão. No fígado eNOS produz quantidade basal de óxido nítrico, que pode ser aumentada em resposta ao fluxo sangüíneo. Hepatócitos e células de Kupffer produzem altas concentrações de óxido nítrico em resposta a interleucina-1. Em ambas as células a produção de óxido nítrico é mediada pela ação do fator nuclear KB, cuja ativação aumenta a expressão de iNOS. O próprio óxido nítrico é capaz de diminuir a transcrição do gene para iNOS por inibir a ativação do fator nuclear KB.

Durante a isquemia as concentrações de NADPH e oxigênio diminuem. Conseqüentemente diminui a produção de óxido nítrico. Durante a reperfusão há rápido e limitado aumento na produção de óxido nítrico graças a entrada de cálcio para o interior das células, o que estimula a ação da eNOS. Ao mesmo tempo, grande quantidade de arginase é liberada, provocando depleção das reservas de L-arginina aos 30 minutos de reperfusão. Em modelos animais, aumentos de $15 \%$ das concentrações de nitrato e nitrito são registrados aos 10 min de reperfusão. A oferta de Larginina causa intensa e curta produção de óxido nítrico. $\mathrm{O}$ aumento da dose de Larginina não tem nenhum efeito para a produção de óxido nítrico. Essas observações podem ser explicadas pela provável saturação da eNOS e pela degradação da L-arginina pela ação da arginase.

A indução de iNOs exige várias horas e é pouco provável que níveis relevantes de atividade sejam atingidos antes de $4 \mathrm{~h}$ de reperfusão. Produção dose-dependente de óxido nítrico, segundo a oferta de Larginina somente foi observada após 6 horas de reperfusão. Desde que a produção dose-dependente de óxido nítrico exige a presença de iNOS, sugere-se que 6 horas seja o tempo necessário para a indução do efeito dependente da iNOs. O fator nuclear KB é ativado com uma hora de reperfusão e permanece ativado por 5 horas. A administração de antioxidante durante a reperfusão inibe a expressão do RNAm para iNOS, sugerindo fortemente que o fator nuclear KB seja regulado pelo estresse oxidativo durante a lesão de isquemia e reperfusão. Estudos em modelos animais deficientes para o gene da eNOS ou INOS sugerem que a geração sistêmica ou local de iNOS regulam a reperfusão hepática, e que a ação da iNOS local contribui para a lesão hepática, enquanto eNOS tem papel protetor na lesão de isquemia e reperfusão hepática.

\section{O papel das moléculas de} aderência ${ }^{27,28,29}$

Embora haja grande número de evidências a respeito da importância dos leucócitos para a lesão de isquemia e reperfusão, pouco se sabe a respeito dos mecanismos implicados no recrutamento dos leucócitos para o interior do tecido reperfundido. Há grande interesse no estudo moléculas conhecidas como moléculas de aderência, e que estão associadas ao recrutamento de leucócitos induzidos por isquemia e reperfusão. As três famílias que têm papel significativo nas interações celulares entre leucócitos e endotélio são as selectinas (P-E- e L-), membros da super-família geneimunoglobulina, tais como a molécula de adesão inter-celular-1 (ICAM0-1) e as integrinas. Na fase inicial, que é mediada por selectinas, leucócitos aderem na parede endotelial. P-selectina, que existe em grânulos de plaquetas e nas células endoteliais atua no estágio inicial de interação entre endotélio e leucócitos. Pselectina é imediata e transitoriamente expressa na superfície de células sob estímulo de mediadores inflamatórios como trombina, histamina, complemento e fatos de necrose tumoral. A aderência firme dos leucócitos ao endotélio, sua ativação e subseqüente migração nos tecidos vizinhos são mediados por integrinas (Mac-1 e LFA-1) e proteínas da superfamília geneimunoglobulina (por exemplo ICAM). Embora tenha sido demonstrado que as células sinusoidais hepáticas não contém P-selectina, e que a expressão de P-selectina não é encontrada nos sinusóides hepáticos. Muitos estudos têm implicado o seu papel na lesão de isquemia e reperfusão hepática. Em ratos deficientes no gene para P-selectina demonstra-se que essa molécula de adesão é mediadora da lesão de reperfusão envolvendo seqüestro de 
neutrófilos e plaquetas no fígado. Estudos semelhantes usando animais deficientes em genes para outras moléculas de adesão mostraram que ICAM-1 tem importante papel em mediar a lesão e distúrbios da microcirculação em conjunção com Lselectina. Em contraste a esses estudos, trabalhos usando anticorpo monoclonal para bloquear a ação da P-selectina não mostraram redução do acúmulo de neutrófilos, nem atenuaram a lesão em modelo murino de endotoxemia. Em modelo animal deficiente para dois genes (P-selectina e ICAM-1) a lesão de isquemia e reperfusão (90 minutos de isquemia por reperfusão em tempos variáveis até 6 horas) foi independente da presença das proteínas de adesão. Células endoteliais expressam $\mathrm{Pe}$ E-selectinas, enquanto L-selectinas são encontradas em neutrófilos. O uso de inibidor da atividade da P-selectina (Pselectinaglicoproteína ligande-1) efetivamente diminui a lesão do hepátócito, a aderência de leucócitos e a sua subseqüente migração em modelos animais de lesão de isquemia e reperfusão.

\section{Apoptose 30,31,32,33,34,35 $^{2}$}

Não obstante a morte celular, em situações de isquemia e reperfusão, seja naturalmente atribuídas a necrose celular, tem se reconhecido recentemente outro tipo de morte celular: a apoptose, ou morte celular programada, pode ser ativada durante as fases iniciais da reperfusão após isquemia hepática. Durante a apoptose, uma cascata de eventos bem regulados e dependente de energia, ativa endonucleases específicas resultando em divisão do DNA em 180 fragmentos de pares de bases. O DNA fragmentado e condensado forma os típicos corpos apoptóticos. A apoptose é caracterizada pela ausência de infiltrado inflamatório. As células, que sofreram o processo, são rapidamente removidas pelo sistema retículo-endotelial. A apoptose difere-se da necrose não somente morfologicamente, mas também nos mediadores e nos mecanismos biológicos de lesão. Fator de necrose tumoral-a, espécies reativas de $\mathrm{O}_{2}$ intermediárias, proteases intracelulares tais como as calpaínas, e lipídios, tais como as ceramidas são mediadores envolvidos em vias biológicas que levam a apoptose em várias situações fisiológicas e patológicas e estão ativados em situação de isquemia e reperfusão no fígado. Caspases são cisteinases especifi- camente envolvidas nas fases de iniciação e execução do processo de apoptose. O uso de inibidores específicos dessas enzimas inibe o processo de apoptose, e constitui importante ferramenta farmacológica para o seu estudo. A inibição da apoptose por meio do uso de Z-Asp-2,6-dichlorobenzoyl-oxymetihylketone, um inibidor específico das caspases, tem efeito protetor sobre o fígado em situações de lesão de isquemia e reperfusão. A inibição da apoptose pela ação de droga inibidora da caspase resulta em diminuição da infiltração de neutrófilos e da lesão hepática, sugerindo que a apoptose do tecido hepático possa ser o sinal para a reação inflamatória causada por neutrófilos. Apoptose foi documentada em hepatócitos e células endoteliais humanas durante o transplante hepático. O fenômeno também pode ser documentado em células endoteliais de sinusóides hepáticos em fígados de ratos preservados a frio. Em modelo animal de lesão de isquemia e reperfusão hepática, as células endoteliais mostram sinais de apoptose mais cedo do que o fazem os hepatócitos. Torna-se mais evidente tanto em células endoteliais, como em hepatócitos, quanto maior o tempo de reperfusão. A duração da isquemia também influencia diretamente o grau de apoptose nos tecidos. O estudo das vias biológicas da apoptose em fígado de ratos sugere que os passos iniciais da cascata aconteçam durante o período de isquemia, não obstante os sinais de apoptose somente apareçam durante a reperfusão, causando a isquemia apenas a necrose celular. Embora a apoptose tenha sido observada em várias situações, muitos aspectos do fenômeno, principalmente suas bases moleculares, não estão claros e constituem tentadora área de pesquisa básica.

\section{A cirurgia $^{5,36}$}

Fatores que dizem respeito ao doador, à técnica operatória e ao receptor podem contribuir para a lesão de isquemia e reperfusão. Os doadores estão sujeitos a vários tipos de estresses, tais como isquemia causada por hipotensão ou drogas e efeito de drogas usadas durante o tratamento do doador ainda em vida. Fígados esteatóticos estão diretamente implicados com a disfunção do enxerto e são mais susceptíveis à lesão de isquemia e reperfusão que fígados normais. Outros fatores que podem influenciar o resultado do transplante são o tempo de isquemia fria e normotérmica, diminuição do fluxo venoso portal e fluxo arterial, tempo operatório, episódios de hipotensão durante a cirurgia, e a extensão da isquemia esplâncnica. Vários fatores pós-operatórios, que não a lesão causada por isquemia e reperfusão, podem influenciar a evolução do transplante. Os diagnósticos diferenciais dessas causas de disfunção do enxerto incluem infecções causadas por vírus hepatotróficos ou não hepatotróficos, hepatotoxidade por drogas, doenças biliares, rejeições agudas ou crônicas e trombose da artéria hepática.

\section{As citocinas $^{37}$}

O fator de necrose tumoral (TNF)-a e a interleucina (IL)-1 são as duas principais citocinas implicadas na lesão de isquemia e reperfusão do fígado. Ambas induzem a síntese de IL-8 e regulam a expressão de moléculas de adesão, permitindo assim a interação entre endotélio e leucócitos, o que por sua vez aumenta a produção de citocinas. TNF-a tem importante papel para a quimiotaxia e ativação de neutrófilos e para geração de superóxidos pelas células de Kupffer. IL-1 induz as células de Kupffer a produzir TNF-a, além de regular a produção de radicais livres pelos neutrófilos. A concentração de fator de ativação plaquetário (PAF) aumenta significantemente 12 horas após a reperfusão e atinge o seu pico às 24 horas de reperfusão, tempo em que a lesão é intensa. A produção de PAF é provavelmente resultado da interação entre células de Kupffer e radicais livres. A injeção de antagonista específico de PAF antes da indução da isquemia melhora o fluxo sangüíneo hepático no período de reperfusão. Consegue-se proteção contra a lesão de isquemia e reperfusão do fígado mediante a combinação de oferta de antioxidantes (superóxido dismutase e catalase) e a inibição da ação do TNF obtida por meio do uso de anti-soro neutralizante de TNF. Propõese que PAF induza a ativação de neutrófilos por meio da indução da produção de TNF-a e outra citocina, membro da família da IL-8. Sugere-se que o mecanismo por meio do qual os imunossupressores melhoram a lesão de isquemia e reperfusão do fígado seja por meio da modulação da 
produção de TNF, já que as concentrações séricas de TNF estão claramente diminuídas em animais pré-tratados com imunossupressores e submetidos à lesão de isquemia e reperfusão do fígado. IL-10, citocina antiinflamatória, aparentemente exerce seu efeito por meio da inibição do fator nuclear transcripcional (NF)-kB, já que murinos recombinantes IL-10 suprimem a expressão de mRNA para TNF-a, moléculas de adesão intercelular, com conseqüente diminuição da lesão de isquemia e reperfusão.

Recentes observações oferecem evidências de que o complemento possa ter importante papel na fisiopatologia da lesão de isquemia e reperfusão. A inibição dos efeitos do complemento por meio da administração de drogas 1 minuto antes da reperfusão efetivamente diminuiu os distúrbios da microcirculação hepática após período de período de lesão de isquemia e reperfusão.

\section{Os radicais livres}

\section{Definição $o^{6,38}$}

O termo radical livre designa qualquer átomo ou molécula que exista independentemente e que contenha um ou mais

TABELA 1 - Exemplo de espécies reativas de oxigênio segundo a meia-vida em segundos ( Nota: R é um lipídio, exemplo o linoleato)

\begin{tabular}{lc}
\hline Espécie reativa de oxigênio & Meia-vida (segundos) \\
\hline HO radical Hidroxilar & $10^{-9}$ \\
$\mathrm{HO}_{2}$ radical Hidroxiperoxilar & instável \\
RO radical Alcoxilar & $10^{-6}$ \\
ROO radical Peroxilar & 7 \\
$\mathrm{H}_{2} \mathrm{O}_{2}$ Peróxido de Hidrogênio & enzimático \\
$\mathrm{O}_{2}$ radical Superóxido & enzimático \\
Oxigênio Singleto & $10^{-5}$ \\
Q radical Semiquinona & dias \\
$\mathrm{NO}$ radical Óxido Nítrico & $1-10$ \\
$\mathrm{HOCl}$ ácido Hipocloroso & estável \\
ONOOO- Peroxinitrito & $0,05-1$ \\
\hline
\end{tabular}

Em estados patológicos, radicais livres são produtos do metabolismo da xantina oxidase, neutrófilos ativados, oxidação de catecolaminas, células endoteliais e prostaglandinas. elétrons não pareados nos orbitais externos. O elétron não pareado ocupa um orbital atômico ou molecular isoladamente. Muitos estudos têm responsabilizado o mediador das lesões causadas por isquemia e reperfusão de tecidos. A grande maioria dos radicais livres possui meiavida muito curta, indo de segundos a nanosegundos, sendo capazes de reagir rapidamente com vários compostos ou atingir alvos, como as membranas celulares. A presença de um ou mais elétrons não pareados determina atração para um campo magnético e, algumas vezes, torna a substância altamente reativa. Entre os vários tipos de radicais livres estão aqueles derivados do oxigênio (tabela 1). Um agente oxidante age como receptor de elétrons das moléculas que oxida, enquanto o agente redutor é um doador de elétrons.

O radical hidroxila é o mais reativo dos radicais livres do sistema biológico e é provavelmente o responsável pela maioria das lesões celulares observadas. Halliwell (1992), descreveu-o como a espécie reativa mais terrível, podendo atacar todas as moléculas biológicas, retirando átomos de hidrogênio dos ácidos graxos insaturados das membranas celulares. radical livre derivado do oxigênio como o

\section{Origem dos radicais livres}

A enzima xantina oxidase é importante fonte de radicais livres em tecidos reperfundidos Durante a isquemia, xantina oxidase produzida pela conversão da xantina desidrogenase (conversão D-O) acumulase nos tecidos. A velocidade da D-O conversão é diferente para diferentes tecidos, o que pode explicar a diferente suscetibilidade dos tecidos à isquemia. Durante a isquemia, acumula-se também a hipoxantina, derivada de 5'-monofosfato de adenosina (AMP). A enzima usa oxigênio molecular para converter hipoxantina a xantina, produzindo superóxido no processo (Figura 2). Durante a isquemia, ferro também é liberado nos tecidos. $\mathrm{Na}$ reperfusão superóxidos e peróxido de hidrogênio são produzidos. Superóxido promove a liberação do íon ferroso, de forma que grande quantidade de ferro pode estar disponível para catalisar a conversão de peróxido de hidrogênio em radicais hidroxil.

A geração de radicais livres durante a reperfusão também pode ser explicada pela hipótese mitocondrial: durante a isquemia, há grave diminuição dos componentes da cadeia respiratória localizada na mitocôndria. Durante a reperfusão ocorre produção de ânion superóxido, em razão do aumento da taxa de auto-oxidação de flavina semi-quinona e ubisemi-quinona e NADH-desidrogenase. A concentração de ambas as semiquinonas está aumentada em razão da inibição da transferência dos elétrons na cadeia respiratória. $\mathrm{O}$ ânion superóxido intramitocondrial, incapaz de se difundir para fora da mitocôndria, gera peróxido de hidrogênio por meio da ação da enzima Mn-superóxido dismutase. $\mathrm{O}$ peróxido de hidrogênio difunde-se para o citosol. O resultado da geração de superóxido intramitocondrial será o aumento da concentração de peróxido de hidrogênio em toda a célula. Esse irá reagir com grupos hemes de citocromos citosólicos e intramitocondriais, gerando espécies oxidativas extremamente reativas e capazes de iniciar as lesões observadas. Frutose-1,6 bifosfato parece ter papel protetor da função mitocondrial durante a lesão provocada por isquemia e reperfusão do fígado, por inibir a peroxidação de lipídios durante a reperfusão, e talvez por funcionar como fonte de energia para o tecido isquêmico e funcionar como substrato para a glicólise.

\section{Peroxidação de lipídios $^{40,41}$}

Grande quantidade de componentes celulares é capaz de reagir com os radicais 


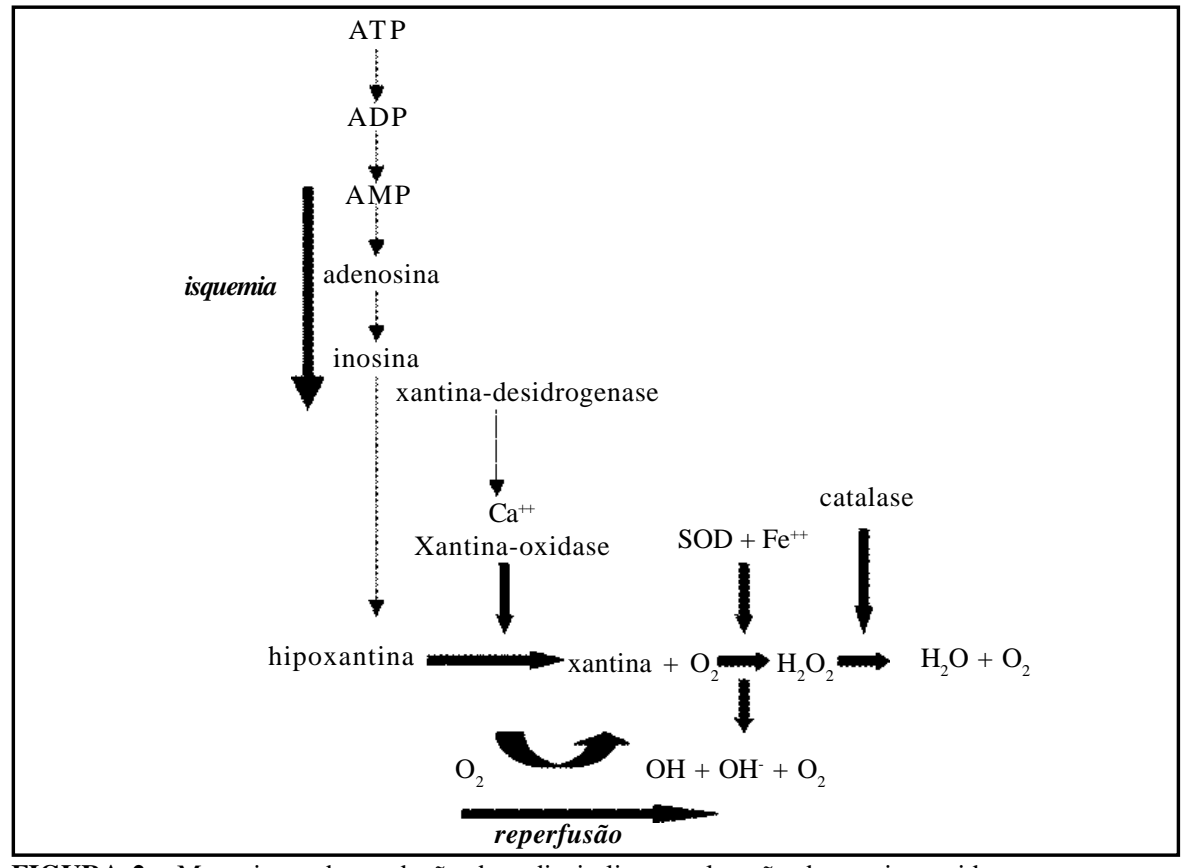

FIGURA 2 - Mecanismo de produção de radicais livres pela ação da xantina oxidase.

livres. São eles as pequenas moléculas de aminoácidos insaturados, bases de ácidos nucléicos carbohidratos e lipídios insaturados das membranas, macromoléculas de proteínas DNA e ácido hialurônico. Agem provocando alterações celulares tais como: desnaturação de proteínas, ligações cruzadas de lipídios e proteínas, inibição da ação de enzimas, mutações nos ciclos celulares, lesão de receptores da superfície celular, oxidação de ácidos graxos e colesterol, alterações na permeabilidade da membrana celular e das organelas, etc. $\mathrm{O}$ principal efeito dos radicais livres é a peroxidação dos lipídios. As membranas celulares são compostas de fosfolípides e ácidos graxos insaturados. Radicais livres de oxigênio causam lesão celular por induzir peroxidação desses lipídios. Tratase de fenômeno complexo iniciado pela abstração de um átomo de hidrogênio de um grupo metileno posicionado entre duas ligações insaturadas na molécula do lipídio. O resultado é a formação de peróxidos de lipídios, ou hidroperóxidos de lipídios. O metabolismo desse último produz malonildialdeído (MDA), o qual pode ser usado como marcador da lipoperoxidação. Apesar da utilidade do MDA como marcador da peroxidação lipídica, os métodos mais usados para sua dosagem não são simples e são pouco confiáveis. A maneira clássica de determinação do MDA por meio do método da determinação dos reagentes ao ácido thiobarbitúrico é afetada pela interferência de muitos agentes e é dificilmente reproduzível. Outros componentes celulares que podem ser lesados pelos radicais livres são as proteínas, especialmente aquelas que contém ácido nucléico, moléculas insaturadas ou moléculas com o radical $\mathrm{SO}_{4}$.

\section{Mecanismos de defesa contra os radicais livres ${ }^{6,42,43,44}$}

Os seres vivos possuem mecanismos endógenos para reagir aos efeitos de radicais livres. Há grande número de substâncias exógenas que podem ser usadas para esse fim. Esses mecanismos são conhecidos como sistemas antioxidantes de defesa, na proteção ou reparação de moléculas agredidas pela oxidação. São eles os seqüestradores de radicais livres, os inibidores da produção dos radicais e os antioxidantes. Entre Os seqüestradores de radicais livres estão: 1) superóxido dismutase, que é metaloenzima endógena que catalisa a reação de dismutação do superóxido $\mathrm{O}_{2}^{-}$;2) catalase, que é hemeproteína que catalisa a reação do peróxido de hidrogênio em água e oxigênio ${ }^{43,90,145}$ glutationa e glutationa peroxidase, que neutralizam os radicais hidroperóxidos intracelulares em água. Há os antioxidantes não enzimáticos, tais como a ceruloplasmina, em razão da sua capacidade de metabolizar o íon superóxido; a transferrina e a lactoferrina que inibem a peroxidação lipídica ferro-dependente, além da albumina, mioglobina, ferritina, e pequenas moléculas não enzimáticas, tais como ácido ascórbico e o a-tocoferol, que age por inibir a propagação de radicais livres dentro da membrana celular, carotenóides, glutationa, bilirrubina, ubiquinona e ácido úrico. Dentre as substâncias exógenas estão o manitol, considerado excelente varredor de radicais livres e o alopurinol, que oferece proteção contra radicais livres por inibir a sua produção, pois se trata de molécula sintética semelhante à hipoxantina, e funciona como inibidor competitivo da xantina-oxidase. Há ainda os antioxidantes, definidos como qualquer substância que, estando presente em baixa concentração, diminui ou previne a oxidação de seu substrato oxidável que podem ser proteínas, lipídios, carboidratos ou ácidos nucléicos.

\section{Os antioxidantes}

Durante a reperfusão há aumento da produção de radicais livres provocado pela ativação de células de Kupffer e de neutrófilos, ação da xantina oxidase, conversão da adenosina a xantina e hipoxantina, e conversão de óxido nítrico a peróxinitrito. Antioxidantes endógenos resistem aos danos provocados pelos radicais livres. Entretanto, estudos em modelos de lesão por isquemia e reperfusão hepáticas mostram que suas concentrações caem durante a fase de reperfusão, provavelmente em razão da degradação desses antioxidantes causada pelo aumento da atividade dos radicais livres. Superóxido dismutase, alopurinol, $\mathrm{N}$-acetilcisteína e a-tocoferol atenuam a lesão por isquemia e reperfusão. Lavagem do fígado antes do enxerto com solução de Carolina Rinse, rica em antioxidantes, aumenta a sobrevida do enxerto.

\section{Radicais livres e o fígado reperfundido ${ }^{45}$}

O papel da lipoperoxidação de lipídios, assim como o papel dos radicais livres na lesão de isquemia e reperfusão do fígado é controverso. Não há evidências de que quantidades suficientes de radicais livres sejam geradas pelos hepatócitos para vencer seus próprios mecanismos de defesa contra a oxidação. Mesmo assim, inibidores da xantina-oxidase dados no 
pré-operatório resultam em evidente efeito hepatoprotetor quando comparados aos animais controles, efeito que pode ser mais importante que os efeitos protetores de seqüestradores de radicais livres dados no pré-operatório. Propõe-se que as espécies reativas de oxigênio sejam geradas por células de Kupffer e por neutrófilos recrutados pela reperfusão. A geração de radicais livres na reperfusão pode não ser causada pela conhecida conversão da xantina-desidrogenase a xantinaoxidase, e sim mediada pela geração de radicais hidroxil, não obstante os efeitos já citados de inibidores da xantina-oxidase. Há resultados de trabalhos bem conduzidos que sugerem que espécies ativas de oxigênio e a peroxidação de lipídios têm importante papel na patogênese da lesão de isquemia e reperfusão do fígado, e que a extensão da lesão está correlacionada com o conteúdo de MDA nos tecidos reperfundidos. Por outro lado, trabalhos usando parâmetros com alta sensibilidade e especificidade para lipoperoxidação (ácidos hidroxi-eicosatetraenóicos e F2isoprostanos), sugerem ser pouco provável que a lipoperoxidação seja o mecanismo primário de lesão do parênquima hepático durante a reperfusão, embora não se possa excluir que a lipoperoxidação possa ser importante mecanismo de lesão em compartimentos limitados do fígado, ou seja, as células endoteliais, que estão próximas das fontes de oxigênio reativo (células de kupffer e neutrófilos) e não possuem as enzimas antioxidantes que naturalmente estão presentes nos hepatócitos e os protegem da lesão por radicais livres de oxigênio. Estudos in vivo sugerem que a isquemia irreversível do fígado do rato está associada com a lipoperoxidação de lipídios, mas que outras células, que não os hepatócitos, são o alvo desse tipo de lesão.

\section{Considerações finais}

A lesão de isquemia e reperfusão do fígado transplantado é fenômeno complexo e pouco compreendido. Envolve numerosas vias metabólicas e mecanismos fisiopatológicos ainda não esclarecidos. As questões que se levantam são incontáveis e as possibilidades de pesquisa são ilimitadas. Pode-se estudar os mecanismos sub-celulares envolvidos na lesão, tais como o papel das diferentes organelas celulares, ou dos diferentes compartimentos e membranas celulares e seus mecanismos de transdução de sinais, o controle e a importância dos mecanismos vasculares, incluindo aí a função do endotélio e de seus vários derivados metabólicos, principalmente o óxido nítrico, o papel dos diferentes grupos celulares (células de Kupffer, leucócitos, etc), a importância da peroxidação de lipídios, o papel de citocinas, das proteínas da fase aguda da resposta inflamatória, de hormônios, do choque sistêmico, etc. Pode-se pensar em estudar os efeitos sistêmicos ou os efeitos que a lesão de isquemia e reperfusão do fígado pode causar em órgãos remotos, como rins, o pulmão e o sistema esplâncnico, assim como as várias e ainda pouco estudadas repercussões metabólicas para o fígado que sobrevive à lesão. Pode-se explorar os mecanismos de proteção hepática e/ou endotelial, tais como o uso de drogas, soluções de conservação hepática, doadores do óxido nítrico, etc. Podese investigar a resistência dos diferentes grupos celulares hepáticos à lesão de isquemia e reperfusão. Área de enorme interesse para pesquisa concentra-se na investigação dos mecanismos nucleares envolvidos na origem e na manutenção da lesão. Todas essas investigações podem envolver estudos dos fenômenos de maneira tempo-dependente e em diferentes espécies de animais de laboratório. Para cada um desses ricos campos de pesquisa há grande número de perguntas a serem respondidas e, a cada vez que se responde a uma delas, novas dúvidas surgem. Há grande número de ferramentas à disposição dos investigadores. Desde o rico armamentário das técnicas de biologia molecular, até os estudos fisiológicos "in vitro", e "in situ”, às provas bioquímicas, morfológicas e farmacológicas, os estudos de respiração mitocondrial e lipoperoxidação. Dispõe-se também de rico arsenal farmacológico, que permite o estudo de vias metabólicas e mecanismos de transdução de mensagens inter e intracelulares, além do comportamento dos diferentes tipos de NOS diante dos mais variados estímulos. O resultado dessas investigações nos proporcionará o entendimento do complexo fenômeno da lesão por isquemia e reperfusão, o que permitirá o desenvolvimento de novas drogas terapêuticas, e implicará em melhores resultados para pacientes submetidos a transplante de órgãos e para pacientes que sofrem situações agudas em que a reperfusão de tecidos isquêmicos seja inevitável.

Com base nestes conceitos planejou-se e executou-se um extenso protocolo experimental na Divisão de Cirurgia Experimental do Departamento de Cirurgia e Anatomia da Faculdade de Medicina de Ribeirão Preto da Universidade de São Paulo. Esta investigação teve por objetivo avaliar in vitro da função endotelial de artérias hepáticas caninas, comparando-a, do ponto de vista de evolução temporal, ao aparecimento da lesão hepática. Foram estudados 24 cães de ambos os gêneros divididos nos seguintes grupos: 1) Controle - cães operados sem sofrer isquemia ou reperfusão hepática; 2) I60 - cães submetidos a 60 minutos de isquemia da artéria hepática e do fígado; 3) I30/R60 - cães submetidos a 30 minutos de isquemia e 60 minutos de reperfusão e; 4) I45/R120 - cães submetidos a 45 minutos de isquemia e 120 minutos de reperfusão da artéria hepática e do fígado. A artéria hepática foi estudada em câmaras de órgãos ("organ chambers"), obtendo-se curvas dose-respostas para acetilcolina, fluoreto de sódio, fosfolipase C, ionóforo do cálcio A23187, poli-L-arginina, nitroprussiato de sódio e isoproterenol. Amostras do fígado foram obtidas para dosagem de malonildialdeído (MDA), para estudo da respiração mitocondrial por meio de traçados polarográficos e para avaliação do potencial de membrana mitocondrial. Sangue foi obtido para dosagem de transaminases e desidrogenase lática (DHL). Não se observaram diferenças entre os grupos para os relaxamentos arteriais para todas as drogas que testam os principais passos da via de liberação do óxido nítrico. O grupo I45/R120 apresentou evidente aumento dos valores de transaminases e DHL, aumento dos valores do MDA e tendência à diminuição da respiração mitocondrial estimulada por ADP, sem haver prejuízo irreversível para a fosforilação oxidativa ou para o potencial de membrana mitocondrial.O conjunto dessas observações demonstrou que no território hepático a lesão hepatocelular do fígado pode se documentada mais precocemente do que a lesão do endotélio da artéria principal que irriga o órgão. Esse resultado permite sugerir que o óxido 
nítrico derivado do endotélio da artéria hepática não contribui para as fases iniciais da lesão por isquemia e reperfusão do fígado canino.

\section{Referências}

1. Lake JR, Gournay J. Liver transplantation. In: Sleisenger, Fordtran's (eds). Gastrointestinal and liver diseases. 6ed. 1997; 2:1405.

2. Lefer AM, Ma X-L. Endothelial dysfunction in the splanchnic circulation following ischemia and reperfusion. J. of Cardiovasc Pharmacol 1991; 17:S186-S90.

3. Lemasters JJ, Thurman RG. The many facets of reperfusion injury. Gastroenterology 1995; 108:1317-20.

4. De Wolfe A. Monitoring and handling of reperfusion. Liver Transplant Surg 1997; 3:459-61.

5. Henderson JM. Liver transplantation and rejection: an overview. Hepatogastroenterol 1999; 46(suppl 2):1428-84.

6. Grace PA. Ischemia-reperfusion injury (review) Br J of Surg 1994; 81:637-47.

7. Welbourn CRB, Goldman G, Paterson IS, Valeri CR, Shepro D, Hechtman HB. Pathophysiology of ischemia-reperfusion injury: central role of the neutrophil. Br J Surg 1991; 78:651-5.

8. Shiratori Y, Kiriyama H, Fukushi Y, Nagura T, Takada H, Hai K, Kamii K. Modulation of ischemia-reperfusion-induced hepatic injury by Kupffer cells. Dig Dis. Sci 1994; 39:1265-72.

9. Nakamitsu A, Hiyama E, Imamura Y, Matsuura Y, Yokoyama T. Kupffer Cell function in ischemic and nonischemic livers after hepatic partial ischemia/reperfusion. Surg Today 2001; 31:140-8.

10. Zhang S, Jin MB, Zhu Y et al. Effects of endogenous adenosine augmentation oh ischemia and reperfusion injury to the liver. Transplant Proc 1997, 29:1236-40.

11. Yin DP, Sankary HN, Chong AS, Ma LL, Shen J, Foster P. Williams JW. Protective effect of ischemic preconditioning on liver preservation-reperfusion injury in rats. Transplantation 1998; 66:152-7.

12. Hur GM, Ryu YS, Yun HY, Jeon BH, Kim YM, Seok JH, Lee JH. Hepatic ischemia/ reperfusion in rats induces iNOS gene transcription by activation of NF-kB. Biochem. Biophys Res Commun 1999; 261:917-22.

13. Pannen BH, Al Adili F, Bauer M Clemens MG, Geiger KK. Role of endothelins and nitric oxide in hepatic reperfusion injury in the rat. Hepatology 1998; 27:755-64.

14. Kawamura E, Yamanaka N, Okamoto E, Tomoda F, Furukawa K. Response of plasma and tissue endothelin-1 to liver ischemia and its implication in ischemia-reperfusion injury. Hepatology 1995; 21:1138-43.

15. Miranda LEC. O papel da artéria hepática na lesão por isquemia e reperfusão do fígado canino: estudo in vitro do relaxamento arterial dependente de óxido nítrico. [Tese de Doutorado, 179p] São Paulo - Faculdade de Medicina de Ribeirão Preto, Universidade de São Paulo, 2002.

16. Barry A. The role of nitric oxide in hepatic metabolism. Nutrition 1998;14:376-90.

17. Liu P, Yin K, Nagele R, So WP. Inhibition of oxide nitric synthase attenuates peroxynitrite generation, but augments neutrophil accumulation in hepatic ischemia-reperfusion in rats. J Pharmacol Exp Ther 1998; 284:1139-46.

18. Angele MK, Fitzal F, Smail K, Knoferl MW, Schwacha MG, Ayala A, Wang P, Chaudry IH. L-arginine attenuates traumahemorrhage-induced liver injury. Crit Care Med 2000; 28:3242-8.

19. Wang Y, Marsden PA. Nitric oxide synthases: gene structure and regulation. Adv Pharmacol 1995; 34:71-9.

20. Ozakyol AH, Tuncel N, Saricam T, Uzuner K, Ak D, Gurer F. Effect of nitric oxide inhibition on rat liver ischemia reperfusion injury. Pathophysiology 2000; 7:183-8.

21. Liu P, Xu B, Quilley J, Wong PY. Peroxynitrite attenuates hepaticreperfusion injury. Am J Physiol Cell Physiol 2000; 279:1970-7.

22. Shah V, Haddad FG, Garcia-Gardena G, Frangos JA, Mennone A, Groszmann RJ, Sessa WC. Liver sinusoidal endothelial cells are responsable for nitric oxide regulation of resistence in the hepatic sinosoids. J Clin Invest 1997; 100:2923-30.

23. Shiratori Y, Ohmura K, Hikiba Y, Matsumura M, Nagura T, Okano K, Kammi K, Omata M. Hepatocyte nitric oxide production is inuced by Kupffer cells. Dig Dis Sci 1998; 43:1737-45.

24. Stewart AG, Barker JE, Hickey MJ. Nitric oxide in ischaemia-reperfusion injury. In Grace PA, Mathie, RT editors. Ischaemiareperfusion injury. Ist ed. Oxford: Blacwell Science 1999; 180-95.

25. Hobbs AJ, Ignarro LJ. Chemistry and molecular biology of nitric oxide synthesis. In Mathie, R.T.; Griffith, T.M. (Eds.) London:Imperial College Press 1999; 5281.

26. Lee VG, Johnson ML, Baust J, Laubach VE, Watkins SC, Billiar TR. The roles of iNOS in liver ischemia-reperfusion injury. Shock; 2001:16:355-60.

27. Crockett-Torabi E. Selectins and mechanisms of signal transduction (review). J Leukoc Biol 1998; 63:1-14.

28. Dulkanchainun TS, Goss JA, Imagawa DK, Shaw GD, Anselmo DM, Kaldas F, Wang T, Zhao D, Busutill AA, Kato H, Murray NG, Kupiec-Weglinski JW, Busutill RN. Reduction of hepatic ischemia/reperfusion injury by a soluble P-selectin glycoprotein ligand-1. Ann Surg 1998; 227:832-40.

29. Essani NA, Fisher MA, Simmons CA, Hoover JL, Farhood A, Jaeschke H. Increased P-selectin gene expression in the liver vasculature and its role in the pathophysiology of neutrophil-induced liver injury in murine endotoxin shock. J Leuko Biol 1998; 63:288-96.

30. Kerr JFRWA, Currie AR. Apoptosis: a basic biological phenomenon with wide-ranging implications in tissue kinetics. Br J Cancer 1972; 26:239-57.

31. Majno G, Joris I. Apoptosis, oncosis and necrosis: an overview of cell death. Am J Pathol 1995;146: 3-15.

32. Patel T, Gores G. Apoptosis and hepatobiliary diseases. Hepatology 1995; 21:1725-41.

33. Gao W, Bentley R, Madden JF, Clavien PA. Apoptosis in sinusoidal endothelial cells is a critical mechanism of preservation injury in rat liver transplantation. Hepatology, 1998; 27:1652-60.

34. Borghi-Scoazec G, Scoazec JY, Durand F, Bernuau J, Belghiti J, Feldmann G, Henin D, Degott C. Apoptosis after ischemiareperfusion in human liver allografts. Liver transplat Surg 1997; 3:407-15

35. Gujral SP, Bucci TJ, Farhood A, Jaeschke H. Mechanism of cell death during warm hepatic ischemia-reperfusion in rats Apoptosis or necrosis? Hepatology; 2001; 33:397-405

36. Adam R, Reynes M, Johann M, Astarcioglu I, Kafelzis I, Castaing D, Bismuth $\mathrm{H}$. The outcome os steatotic grafts in liver transplantation. Transplant Proc 1991; 23: 1538-40.

37. Pober JS. Cytokine-mediate activation of vascular endothelium: physiology and pathology. Am J Pathol 1998; 133:426-33.

38. Halliwell B, Gutteridge JMC, Cross CE. Free radicals, antioxidants, and human disease: Where are we now? J Lab Clin Med 1992. 119:568-620.

39. Perrota V, Shinaider A. Radicais livres de oxigênio: importância na fisiopatologia das lesões isquêmicas viscerais. An. Acad Med 1992; 152:22-7.

40. Del Maestro R, Thaw HH, Bjork J, Planker $\mathrm{M}$, Arfors KE. Free radicals as mediators of tissue injury. Acta Physiol Scand Suppl 1980; 492:43-57.

41. Janero DR. Malondialdehyde and thiobarbituric acid-reactivity as diagnostic indices of lipid peroxidation and peroxidative tissue injury. Free Radic Biol Med 1990; 9:515-40.

42. Freeman BA, Crapo JD. Biology of disease: free radicals and tissue injury. Lab Invest 1982;47(5):412-26.

43. Machlin LJ, Bendich A. Free radical tissue damage: protective role of antioxidant nutrients. FASEB J 1987; 1:441-45.

44. Halliwell B, Gutteridge JMC. Free Radicals In Biology And Medicine. 2ed Oxford, Clareton; 1989.

45. Nauta RJ, Tsimoyiannis E, Uribe M, Walsh DB, Miller D, Butterfield A. Oxygen-derived free radicals in hepatic ischemia and reperfusion injury in the rat. Surg Gynecol Obstet 1990; 171:120-5. 
Miranda LEC, Viaro F, Ceneviva R, Évora PRB. The experimental basis of hepatic ischemia-reperfusion injury: review. Acta Cir Bras [serial online] 2004 Jan-Feb;19(1). Available from URL: http://www.scielo.br/acb.

ABSTRACT - Hepatic transplantation has become the main treatment for patients with terminal hepatic disease. Whatever the success of such surgery, the hepatic dysfunction associated with liver transplantation is an important cause of morbidity and mortality. Paradoxically, on restoring the blood supply, the liver is subjected to a further insult, aggravating the injury already caused by ischemia. This complex phenomenon is termed ischemia-reperfusion injury and involves endothelial cell dysfunction, leukocyte entrapment, platelet aggregation, oxidant stress and hepatic microcirculatory perfusion failure. This review discusses the physiopathlogicals mechanisms of liver ischemiareperfusion injury.

KEY WORDS - Ischemia-reperfusion injury. Liver.

Conflito de interesse: nenhum

Fonte de financiamento: nenhuma

Correspondência:

Paulo Roberto B.Evora

Rua Rui Barbosa, 367/15

14015-120 Ribeirão Preto - SP

prbevora@keynet.com.br

Data do recebimento: $28 / 12 / 2003$

Data da revisão: 12/01/2004

Data da aprovação: 22/01/2004

\section{JORNADA CONJUNTA DE ENSINO E PESQUISA EM CIRURGIA EXPERIMENTAL}

Local: Academia Nacional de Medicina (ANM) - 175 anos

Data: 6 de maio de 2004 - Quinta-feira

Horário: 14 às 20 horas

PATROCINADORES: Academia Nacional de Medicina, sociedade para o desenvolvimento da pesquisa em cirurgia (SOBRADPEC/REGIONAL RJ), INSTITUTO DE PÓS-GRADUAÇÃO MÉDICA CARLOS CHAGAS, DEPARTAMENTO DE CIRURGIA DA FACULDADE DE MEDICINA DA UNIVERSIDADE FEDERAL DO RIO DE JANEIRO, COLÉGIO BRASILEIRO DE CIRURGIÕES

\section{Comissão Organizadora}

Profs. Pietro Novellino, Alberto Schanaider, Aloysio de Salles Fonseca, Ernani Vitorino Aboim e Umberto Perrotta

\section{Comissão Científica:}

Profs. Aderbal Magno Caminada Sabra, Aníbal Gil Lopes, Henrique Murad, Hiran Silveira Lucas, José Augusto da Silva Messias, Levão Bogossian, Luis Felipe da Silva, Orlando Marques Vieira, Roberto Saad, Ronaldo Antônio Reis Vianna Salles, Saul Goldenberg, Talita Romero Franco 